\title{
Disseminação do vírus da doença de Aujeszky, envolvendo o comércio de reprodutores suínos de reposição
}

[Spread of virus of Aujeszky's disease by the trade of replacement swine breeders]

\author{
N. Mores ${ }^{1}$, A.L. Amaral ${ }^{1}$, L. Ventura ${ }^{2}$, J.R.C. Zanella ${ }^{1}$, A. Mori ${ }^{3}$, J.A. Dambrós ${ }^{4}$ \\ G. Provenzano ${ }^{4}$, I. Bisolo ${ }^{3}$ \\ ${ }^{1}$ Embrapa Suínos e Aves \\ Caixa Postal 21 \\ 89700-000 - Concórdia, SC \\ ${ }^{2}$ Convênio ACCS, AINCADESC e Embrapa Suínos e Aves \\ ${ }^{3}$ COPÉRDIA - Concórdia, SC \\ ${ }^{4}$ CIDASC - Concórdia, SC
}

\begin{abstract}
RESUMO
Relata-se a disseminação da infeção pelo vírus da doença de Aujeszky (VDA) a partir da comercialização de reprodutores suínos oriundos de duas granjas de reprodutores suídeos certificada (GRSC) que tiveram surto da DA. Após a confirmação do diagnóstico de DA, os suínos comercializados 37 a 45 dias anteriores aos surtos foram recolhidos, submetidos ao exame sorológico para o VDA e enviados ao abate. Nos rebanhos-destino foram realizados exames sorológicos para o VDA 17 a 37 dias após o recolhimento, naqueles que estavam lojados nas baias vizinhas àquelas onde haviam sido alojados os suínos comprados; seis meses mais tarde, foi realizada outra sorologia por amostragem dos reprodutores. No total, 52 rebanhos compraram suínos das duas granjas, e, destes, 37 (69,8\%) receberam, pelo menos, um animal com sorologia positiva para o VDA. Somente sete $(18,9 \%)$ deles apresentaram sorologia positiva para o VDA, e em 30 (81,1\%), não houve indícios de disseminação da infecção. A contaminação pelo VDA de granjas GRSC representa enorme potencial para a disseminação da infecção, por meio do comércio de suínos de reposição. A rastreabilidade dos animais comercializados em um período anterior ao diagnóstico, com imediata remoção dos lotes de suínos dos rebanhos-destino, evitou a disseminação da infecção.
\end{abstract}

Palavras-chave: suíno, vírus, Aujeszky, epidemiologia

\begin{abstract}
It was reported the spreading of the infection caused by the virus of Aujesky's disease (VAD) by the commercialization of breeders originated from two pigs farms GRSC (Farms of Certified Swine Breeders FCSB) which had an outbreak of Aujeszky's disease. After the positive diagnosis of Aujesky's disease, the pigs traded from 37 to 45 day before the outbreaks were removed from the herd, bled for serological exams for the VAD and sent to slaughterhouses. The herds which received these pigs were serologically tested for the VAD, 17 to 37 days after the removal of the animals. Serological tests were also performed in pigs lodged at neighboring cages to those which had been lodged with the pigs bought and a sampling test was done six months later. Thus, 52 flocks bought pigs from the farms 1 and 2. From those, 37 (69.8\%) received at least one serum-positive pig for the VAD. Only seven (18.9\%) of them were infected and 30 (81.1\%) pigs showed no indications of infection by the VAD. The occurrence of VAD in FCSB farms represents huge potential for spreading of the VAD, by the trade of replacement pigs. The traceability investigation and removal of the animals traded before the diagnosis, with immediate removal of the positive lots of pigs at the destiny herd, avoided the spread of the infection.
\end{abstract}

Keywords: swine, disease, virus, Aujeszky, epidemiology

Recebido em 16 de maio de 2007

Aceito em 29 de outubro de 2007

E-mail: mores@cnpsa.embrapa.br 


\section{INTRODUÇÃO}

A doença de Aujeszky (DA) é uma enfermidade infectocontagiosa, causada por um herpesvírus de notificação oficial, pertencente ao código zoossanitário internacional do Office International des Épizooties (OIE), com grande impacto econômico para a suinocultura. O primeiro relato da DA no Brasil é de 1912 (Akkerman, 1964) e em Santa Catarina de 1984 (Kruge et al., 1993).

Os suídeos são considerados reservatórios naturais do vírus da DA e têm infecção latente (Davies e Beran, 1980), o que não acontece com outras espécies animais (Kruge et al., 1993). Nestes, sob certas condições de estresse, o vírus pode ser reativado, resultando em eliminação e transmissão para animais susceptíveis (Horwarth, 1969). No Brasil a comercialização e distribuição de animais destinados à reprodução somente é permitida por granjas de reprodutores suídeos certificadas (GRSC), que são livres para várias doenças, incluindo a DA (Instrução..., 2002).

Para o controle da doença, podem ser usadas vacinas marcadas mortas ou vivas e deletadas para alguma glicoproteína (gp). Tais vacinas mostram-se eficientes na redução ou mesmo no bloqueio da transmissão do VDA e estão disponíveis para programa de erradicação, baseado na diferenciação entre animais vacinados e infectados (Duinof e Vesseur, 2004). No Brasil, o uso de vacina contra DA é controlada pelo Ministério da Agricultura Pesca e Abastecimento (MAPA), que somente permite o uso de vacinas deletadas para a gp1.

Em abril de 2001, foi iniciado um programa de erradicação dessa doença no Estado de Santa Catarina, baseado na vacinação obrigatória e no despovoamento gradativo nas granjas com surto ou com alta prevalência $(>10 \%)$ e sorologia diferencial com eliminação dos positivos nos rebanhos com baixa prevalência (Morés e Zanella, 2003). O objetivo deste trabalho é relatar a disseminação da infeção pelo VDA a partir da comercialização de reprodutores suínos de duas granjas GRSC que tiveram surto da DA.

\section{MATERIAL E MÉTODOS}

A GRSC 1, com 140 matrizes, produzia e comercializava fêmeas F1 e machos híbridos para reposição aos rebanhos comerciais. A partir da constatação dos primeiros sinais clínicos da doença em 30 de setembro de 2001, a granja foi interditada e a venda de animais para reprodução foi suspensa. Em 5 de outubro de 2001, foi confirmado o diagnóstico de DA, por meio do exame histológico e isolamento viral. A partir daí, todos os suínos que tinham sido vendidos na última semana de agosto e no mês de setembro de 2001, oriundos de 36 rebanhos, foram recolhidos em 12 de outubro de 2001. No mesmo dia de recolhimento colheu-se sangue para realização da sorologia para o VDA, seguido de abate dos animais. Como os suínos vendidos na última semana de agosto/01, e que haviam sido recolhidos, apresentaram resultados sorológicos negativos para o VDA, os comercializados anteriormente a essa data não foram investigados. Nos rebanhos que receberam animais soropositivos, foram realizadas duas sorologias para o VDA. A primeira sorologia foi realizada aos 30 - 37 dias após a retirada dos suínos soropositivos, naqueles das baias vizinhas onde os soropositivos haviam sido alojados. A segunda sorologia foi realizada aos 4,0 - 5,5 meses depois, utilizando uma amostragem no plantel de reprodutores da granja, que considerou a prevalência estimada de $5 \%$ e nível de confiança de $95 \%$.

A GRSC 2, com 280 matrizes, produzia e comercializava fêmeas F1 destinadas a reposição de rebanhos comerciais. A partir da constatação dos primeiros sinais clínicos da doença em 15 de junho de 2002, a granja foi interditada e a venda de animais para reprodução foi suspensa. Em 21 de junho de 2002, foi confirmado o diagnóstico de DA, por meio do exame histológico e do isolamento viral. Nos dias 23 e 24 de junho de 2002 , todos os suínos que tinham sido vendidos em maio e na primeira quinzena de junho, isto é, 45 dias anteriores ao surto, oriundos de 16 rebanhos, foram recolhidos. Como já descrito, procedeu-se à coleta de sangue e ao abate imediato dos animais. Como os suínos vendidos na primeira semana de maio apresentaram resultados sorológicos negativos para o VDA, os comercializados anteriormente a essa data não foram investigados. Nos rebanhos que receberam suínos soropositivos, 17-18 dias após a retirada desses animais, foi realizada uma sorologia para o VDA nos animais das baias vizinhas onde os soropositivos haviam sido alojados. 
Todos os rebanhos que receberam suínos não possuíam instalações de quarentena, por isso os animais de reposição comprados eram alojados diretamente nas instalações de cobrição/gestação, porém em baias separadas dos demais animais da granja.

Os exames sorológicos dos suínos não vacinados foram realizados com um kit Elisa de triagem. Os soros que resultaram positivos foram submetidos à prova de soroneutralização. Os soros dos suínos vacinados foram testados com o kit Elisa diferencial gp $1^{1}$.

Nas duas granjas, logo após o diagnóstico da doença, foi instituído um programa de vacinação do plantel contra a DA com vacina morta e deletada para gp1; passados os sintomas clínicos, os rebanhos foram despovoados, conforme preconiza o Programa Estadual de Erradicação da DA (Morés e Zanella, 2003). Esses procedimentos também foram adotados nos rebanhos-destino que manifestaram sinais da DA ou que apresentaram alta soroprevalência para o VDA $(>10 \%)$. Os rebanhos que apresentaram baixa soroprevalência para o VDA, igual ou menor que $10 \%$, foram vacinados e incluídos no programa de erradicação da DA por sorologia diferencial e eliminação dos reprodutores positivos.

\section{RESULTADOS E DISCUSSÃO}

Os resultados quanto aos rebanhos envolvidos em cada caso epidemiológico estudado estão na Tab. 1. No período investigado, 52 rebanhos compraram suínos das granjas 1 e 2 e destes, 37 $(69,8 \%)$ receberam pelo menos um animal com sorologia positiva para o VDA. Dos 37 rebanhos que receberam suínos soropositivos, $30(81,1 \%)$ não foram infectados pelo VDA. Nos casos epidemiológicos das granjas 1 e 2, os rebanhos que receberam suínos no período estudado tinham, respectivamente, entre 5 a 155 e 18 a 170 matrizes.

Tabela 1. Resultados clínicos e sorológicos dos rebanhos envolvidos em dois casos epidemiológicos de doença de Aujeszky

\begin{tabular}{|c|c|c|c|c|c|c|}
\hline \multirow{2}{*}{ Granja } & \multirow{2}{*}{$\mathrm{N}^{*}$} & \multicolumn{2}{|c|}{ Sorologia } & \multirow{2}{*}{$\begin{array}{c}\text { Desenvolveram } \\
\text { DA }\end{array}$} & \multirow{2}{*}{$\begin{array}{l}\text { Sorologia } \\
\text { positiva }\end{array}$} & \multirow{2}{*}{$\begin{array}{c}\text { Sorologia } \\
\text { negativa }\end{array}$} \\
\hline & & Negativa & Positiva & & & \\
\hline 1 & 36 & 10 & 26 & 3 & 4 & 19 \\
\hline 2 & 16 & 5 & 11 & 0 & 0 & 11 \\
\hline Total & 52 & 15 & 37 & 3 & 4 & 30 \\
\hline
\end{tabular}

*Número de rebanhos que receberam suínos de reposição no período estudado.

Os suínos, comercializados pela granja 1 entre 12 a 17 de setembro de 2001 apresentaram sorologia positiva para o VDA, e os vendidos anteriormente a essa data, sorologia negativa. $\mathrm{Na}$ granja 2, os vendidos nos dias 20 e 21 de junho de 2002, apresentaram sorologia positiva para VDA, e os comercializados em maio foram todos negativos. Então, a análise desses resultados e do início dos sintomas clínicos revela que, provavelmente, a infecção pelo VDA na granja 1 ocorreu na primeira semana de setembro, e na granja 2 na primeira quinzena de junho.

Em suínos entre 80 a $100 \mathrm{~kg}$, peso aproximado que as granjas 1 e 2 comercializavam animais de reposição, predominam os sintomas respiratórios associados a hipertermia, anorexia e prostação, enquanto os sintomas nervosos são imperceptíveis (Vannier, 1987). É possível que alguns suínos comercializados tenham apresentado tais sinais um pouco antes do surto, sem que fossem percebidos pelos produtores, até que ocorressem sintomas da DA nos leitões da maternidade. Dos 36 rebanhos que receberam suínos da granja 1, 10 os receberam com sorologia negativa, que corresponde aos animais vendidos na última semana de agosto/01, e 26 os receberam com pelo menos um suíno soropositivo para o VDA. Desses 26 rebanhos, três desenvolveram a DA com confirmação laboratorial pela histopatologia e isolamento viral, quatro apresentaram animais soropositivos, mas sem manifestação da doença, e 19 não apresentaram indícios de disseminação do vírus

\footnotetext{
${ }^{1}$ HerdChek Idexx ${ }^{\circledR}$ - Idexx Laboratories - Westbrook, EUA.
} 
no rebanho, tanto na sorologia dos animais das baias vizinhas quanto na monitoria realizada seis meses mais tarde. Além disso, esses 19 rebanhos foram acompanhados por quatro anos e nenhum deles apresentou indícios da doença. Dos sete rebanhos positivos, seis foram despovoados por apresentarem surto de DA ou alta soroprevalência da infecção $(>10 \%)$ e em um, com baixa soroprevalência da infecção $(2,4 \%)$, o VDA foi erradicado por vacinação e após duas sorologias diferenciais (Morés e Zanella, 2003). Em 9 de dezembro de 2002, essa granja foi considerada livre da infecção após duas sorologias negativas, sendo a primeira em $100 \%$ dos reprodutores e a segunda, em uma amostragem (prevalência estimada em 5\% e confiança de 95\%). A erradicação do VDA nesse rebanho foi favorecida pela baixa prevalência e vacinação do rebanho contra a DA, com vacina deletada.

Segundo Stegeman et al. (1994), porcas vacinadas para VDA podem apresentar soroconversão para o vírus de campo, mas a reativação do VDA raramente ocorre ou, se ocorre, não provoca extensiva difusão. Dos seis rebanhos despovoados, dois passaram a ser apenas terminadores, um abandonou a suinocultura e três repovoaram com leitoas e machos oriundos de GRSC livres da infecção pelo VDA e apresentaram sorologia negativa em monitoria por amostragem cerca de seis meses após o repovoamento.

A granja 2 vendeu lotes de suínos a 16 rebanhos, e destes, 11 receberam pelo menos um animal com sorologia positiva para o VDA. Nenhum deles tornou-se infectado, uma vez que os animais alojados nas baias vizinhas apresentaram sorologia negativa aproximadamente 18 dias após a retirada dos lotes de fêmeas dos rebanhos e, novamente, cerca de seis meses após. Estes rebanhos foram acompanhados por um período de dois anos e nenhum deles apresentou indícios da doença. É importante ressaltar, caso as granjas GRSC sejam contaminadas, o potencial que elas representam na disseminação do VDA, com a comercialização de suínos de reposição.

A certificação sanitária de granjas GRSC emitida pelo MAPA tem validade de seis meses, porém os rebanhos podem se contaminar durante esse período, principalmente quando há ocorrência de surto da doença na região, como foi o caso das granjas estudadas. De qualquer forma, é sempre mais seguro, sob o ponto de vista sanitário, que os produtores adquiram suínos de reposição somente de granjas GRSC, que fazem o controle sorológico a cada seis meses, ao invés de fazê-lo de rebanhos com situação sanitária desconhecida. A introdução de animais portadores do VDA em um rebanho é a principal forma de disseminação da doença (Duinof e Vesser, 2004). Buenfil et al. (2002), em estudo epidemiológico, encontraram Odds ratio de 8,7 para disseminação do VDA quando a reposição de suínos era feita de granjas com estado sanitário desconhecido para esse vírus. As 36 granjas que receberam suínos soropositivos pertenciam ao mesmo sistema integrado e somente receberam suínos das granjas 1 ou 2. Dentre os múltiplos mecanismos pelos quais o VDA pode ser transmitido de um rebanho para outro, o movimento de suínos que estão eliminando o vírus ou quando a doença está na fase de latência, é o mais freqüente (Akkerman, 1964). A difusão primária do VDA entre suínos ocorre por contato nariz-nariz (Anderson et al., 1990; Kruge at al., 1993), porém a transmissão do vírus de suínos recuperados da DA para suínos susceptíveis, através do contato, pode não ocorrer durante certo período em razão da latência estabelecida (Akkerman, 1964). O contato estabelecido entre suínos alojados nas mesmas baias ou baias vizinhas tem maior risco de transmissão do vírus (Anderson et al., 1990), o que justifica a realização da sorologia. Sabe-se, também, que a sobrevivência do vírus aumenta em ambientes úmidos e frios (Davies e Beran, 1981). Assim, o clima na Região Sul do Brasil, subtropical com bastante insolação, certamente não é um fator que favoreça a disseminação do vírus. O VDA pode estabelecer persistência ou latência em suínos por longos períodos, principalmente, em vários tecidos do sistema nervoso central (Beran et al., 1980). Akkerman (1964) não conseguiu isolar o VDA de tecidos de suínos recuperados, após inoculação experimental, e McFerran e Dow (1964) verificaram que a excreção do VDA por leitões expostos ao vírus por via intranasal é limitada após 10 dias. Maes et al. (1983) demonstraram que o período de eliminação do VDA por suínos inoculados é amostra dependente. Em condições de campo, o VDA pode ser eliminado apenas por alguns indivíduos de um grupo de suínos por até um mês após sua introdução. Nos rebanhos que receberam suínos soropositivos para o VDA, a infecção não se 
disseminou e dois fatores podem ter contribuído para tal: a) os animais soropositivos adquiridos não estavam eliminando o VDA no período em que permaneceram no interior das instalações; b) os animais soropositivos ficaram alojados em baias separadas dos demais suínos da granja e por período muito curto, o que impediu ou dificultou sua disseminação. Provavelmente, a rapidez de retirada dos lotes positivos adquiridos para reposição do rebanho-destino foi fundamental para evitar a disseminação da infecção. Em suínos infectados, o período de excreção do VDA é variável, mas pode durar de 10 a 21 dias após a infecção (McFerran e Dow, 1964; Maes et al., 1983), mas muitos deles desenvolvem latência e nesses, a excreção do vírus pode não ocorrer, mas sim ser reativada por condições de estresse (Horwarth, 1969; Kruge et al., 1993).

Neste estudo, não foi possível elucidar a origem da infecção das granjas 1 e 2 pelo VDA. Entretanto alguns aspectos podem ser especulados: 1 - essas granjas recebiam animais de reposição de outras duas granjas-núcleo, também GRSC, que não apresentaram sintomas da DA, nem sorologia positiva para o VDA nas monitorias de rotina do MAPA; 2 - as granjas localizavam-se em uma região de alta densidade de suínos onde, no período, ocorreram focos de DA; 3 - as granjas não eram cercadas, não possuíam área de expedição de suínos distante das instalações e o carregamento de leitões na saída da creche e de suínos de descarte era realizado com caminhões que carregavam animais de outras propriedades com condição sanitária desconhecida.

Em qualquer situação, o suíno é o principal responsável pela disseminação do VDA e a curtas distâncias, os vetores clássicos de contaminação como visitas, banhos, caminhões, moscas e dejetos, representam papel importante na disseminação do VDA (Vannier, 1984). Ademais, em regiões de alta densidade de suínos, onde a infecção pelo VDA é elevada, o vento pode ser o responsável pela passagem da infecção de um rebanho para outro (Vannier, 1984). Entretanto, Buenfil et al. (2002) verificaram que a quarentena de animais de reposição, a existência de cerca periférica, de chuveiro com troca de roupa e calçados pelos trabalhadores e visitantes não estavam associados à presença de anticorpos para o VDA.
A DA, por ser causada por um vírus capaz de induzir latência nos suídeos, é de difícil controle, sendo fundamental que regiões ou mesmo países com suinocultura avançada e que vislumbrem o mercado exportador, implementem medidas de erradicação do VDA.

\section{CONCLUSÕES}

A contaminação de granjas GRSC pelo VDA representa um potencial enorme para disseminação da infecção, por meio do comércio de suínos para reposição. A rastreabilidade dos animais comercializados em um período anterior ao diagnóstico da infecção na granja, com imediata remoção dos lotes de suínos dos rebanhos-destino, reduz a disseminação do VDA.

\section{REFERÊNCIAS BIBLIOGRÁFICAS}

AKKERMAN J.P.W.M. Ziektte van Aujeszky bij het varken in Nederlan. Tijdschr. Dsiergeneeskd., v.89, p.146-159, 1964.

ANDERSON, P.L.; MORRISON, R.B.; MOLITOR, T.W. et al. Factors associated with circulation of pseudorabies virus within swine herds. J. Am. Vet. Med. Assoc., v.196, p.887-880, 1990.

BERAN, G.W.; DAVIES, E.B.; ARAMBULO, P.V. et al. Persistence of pseudorabies virus in infected swine. J. Am. Vet. Med. Assoc., v.176, p.998-1000, 1980.

BUENFIL, J.C.R.; FLEITES,M.A.; LOPEZ, A.A. et al. Risk Factors for Aujeszky's disease in pig herds and detection of fied virus antibodies in fettening pigs in the state of Yucatan, Mexico. Prev. Med. Vet., v.53, p.205-213, 2002.

DAVIES, E.B.; BERAN,G.W. Influence of environmental factors upon the survival of Aujeszky's disease virus. Res. Vet. Sci., v.31, p.32-36, 1981.

DAVIS, E.B.; BERAN, G.W. Spontaneous shedding of pseudorabies virus from clinically recovered post-parturient sow. J. Am. Vet. Med. Assoc., v.176, p.1345-1347, 1980.

DUINHOF, T.F.; VESSEUR, P.C. Pseudorabies successfully eradicated from the netherlands. In: INTERNATIONAL PIG VETERINARY 
SOCIETY CONGRESS, 18., 2004, Hamburg. Proceedings... Hamburg: IPVS, 2004. v.1, p.375.

HORWARTH, J.A. A serologic study of pseudorabies in swine. J. Am. Vet. Med. Assoc., v.154, p.1583-1589, 1969.

INSTRUÇÃO Normativa $\mathrm{n}^{\circ}$. 19 de 15 de fevereiro de 2002. Normas para certificação de granjas de reprodutores suídeos. Brasília: MAPA. Diário Oficial da União, de 1 de março de 2002, n.41, seção 1. p.3-5.

KLUGE, J.P.; BERAN, G.W.; HILL, H.T. et al. Pseudorabies (Aujeszky's disease). In:. Leman, A.D.; STRAW, B.E. (Eds). Disease of swine. 7.ed.Ames: Iowa State University, 1993. p.312323.

MAES, P.K.; HANITZ, C.L.; GUSTAFSON, D.P. Shedding patters in swine of virulente and attenuated pseudorabies virus. Am. J. Vet. Res., v.44, p.2083-2086, 1983.
McFERRAN, J.V.; DOW, C. The excretion of Aujeszky's disease virus by experimentally infected pigs. Res. Vet. Sci., v.5, p.146-159, 1964.

MORÉS, N.; ZANELLA, J.R.C. Programa de erradicação da doença de Aujeszky em Santa Catarina. Concórdia: Embrapa Suínos e Aves, 2003. 50p. (Documentos, 81).

STEGEMAN, J.A.; KIMMAN, T.G.; Van OIRSCHOT, J.T. et al. Spread of Aujeszky's disease virus within pig herds in an intensively vaccinated region. Vet. Rec., v.134, p.327-330, 1994.

VANNIER, P. La Maladie d'Aujeszky: Étad des connaissances et situation actuelle. J. Rech. Porcine France, v.16, p.191-204, 1984.

VANNIER, P. Le virus de la maladie d'Aujeszky et les affections perpiratoires du porc. Rec. Med. Vet., v.163, p.407-417, 1987. 